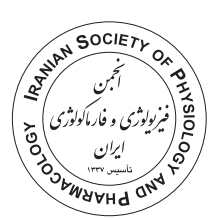

\title{
Protective effect of honey on learning and memory impairment, depression and neurodegeneration induced by chronic unpredictable mild stress
}

\author{
Asiye Rafiee Sardooi, Parham Reisi, Azadeh Yazdi* (D)
}

Department of Physiology, School of Medicine, Isfahan University of Medical Sciences, Isfahan, Iran

\begin{abstract}
Introduction: Chronic stress, which has been prevalent in human life, induce structural changes in the hippocampus. Depression and impairment of memory are serious comorbidities of chronic stress. In this study, we evaluated the impact of an Iranian honey pretreatment on memory deficit, depression and the hippocampal neuronal loss in the chronic unpredictable mild stress (CUMS) model.

Methods: Adult male Wistar rats were divided into the control groups that received water or honey $(0.2$ or $2 \mathrm{~g} / \mathrm{kg})$ and CUMS groups that subjected different, randomly and unpredictable mild stressors for 4 weeks. Ten days before starting the CUMS procedures, the animals received honey $(0.2$ or $2 \mathrm{~g} / \mathrm{kg}$, daily, orally), which was continued until sacrificing. Morris water maze and sucrose performance tests were used to evaluate the spatial learning and memory and depressive-like behavior in the animals respectively. Hippocampus and whole brain samples were collected for further biochemical and histological analysis.

Results: Honey reversed the depression-like behavior and ameliorated the spatial memory deficit induced by CUMS. Also, honey decreased cell death in the hippocampus and reduced the malondialdehyde level in treated animals.

Conclusion: These results revealed that honey diminished learning and memory deficits and depression in chronic stress conditions.
\end{abstract}

\author{
Keywords: \\ Honey \\ Chronic mild stress \\ Learning and memory \\ Neuronal loss \\ Oxidative stress
}

\section{Introduction}

Stress is a biological and protective response to a variety of physiological or psychological stimulations. An increase in glucocorticoid level, as well as noradrenaline, are the first reply of the system (Lindau et al., 2016). Chronic stress, which has been more prevalent in daily human life, can lead to some serious health problems. Several studies have revealed the effect of chronic stress on the central nervous system, including structural changes in the hippocampus (Kim et al., 2015; Surget et al., 2011; Yaribeygi et al., 2017). This part of the brain contributes as a key structural system to spatial learning and memory (Devan et al., 1996). Additionally, chronic stress can cause depression, which is severely associated with learning and memory dysfunction $(\mathrm{Wu}$ et al., 2017). Intense metabolic activities in neuronal cells particularly have made the brain vulnerable to oxidative stress. Some studies showed that the

\footnotetext{
* Corresponding author: Azadeh Yazdi, a.yazdi@mail.mui.ac.ir

Received 22 July 2020; Revised from 7 October 2020; Accepted 27 October 2020
}

Citation: Rafiee Sardooi A, Reisi P, Yazdi A. Protective effect of honey on learning and memory impairment, depression and neurodegeneration induced by chronic unpredictable mild stress. Physiology and Pharmacology 2021; 25: 21-35. http://dx.doi.org/10.32598/ppj.25.1.90 
hippocampus especially is sensitive to oxidative stress (Braak and Braak, 1991; Noseworthy and Bray, 1998; van Velzen et al., 2017; Wang and Michaelis, 2010). Stress is responsible for the generation of free radicals and chronic inflammation, which is associated with neuronal loss in the hippocampus. Neurodegeneration correlated with learning and memory impairment and Alzheimer's disease (Chen et al., 2019; Farajdokht et al., 2012; Mohammadi et al., 2014; Srivastava and Kumar, 2015; Takuma et al., 2012). Meanwhile, oxidative stress in the hippocampus is involved in depression (SouzaMonteiro et al., 2019). Diet, including antioxidant ingredients, may attenuate oxidative damages (Kolosova et al., 2006). Besides, the antioxidant can improve cognitive performance, including learning and memory (Baluchnejadmojarad et al., 2012; dos Santos Junior et al., 2005; Ganji et al., 2017; Ikeda-Douglas et al., 2004). Honey, a natural food product, is a valuable source of antioxidants (Chepulis et al., 2009; Gheldof and Engeseth, 2002; Moloudian et al., 2018). Honey in postmenopausal women improved memory performance (Othman et al., 2011). Short and long-term consumption of honey ameliorate the lipid peroxidation and free radicals mediated molecular destruction in the brain tissue (Oyefuga et al., 2012). A previous experimental study showed that antioxidant activity in the brain and memory function improved by honey administration in lead- induced cognitive problems (Abdulmajeed et al., 2016). Also, clinical and experimental investigations showed that honey could improve the symptoms and biomarkers of depression (Al-Rahbi et al., 2014a; Ali and Hendawy, 2018). Tualang honey protects memory decline and depressive- like behavior induced by noise stress (Azman et al., 2015; Azman et al., 2016). However, Nigerian honey had no significant effect on spatial working memory (Akanmu et al., 2011). Despite the antioxidant capacity of all types of honey, the botanical origin, climate and environmental factors have a great influence on its antioxidant potency (Maurya et al., 2014; Wang et al., 2016). Recent studies have also shown the changes in the antioxidant capacity of Iranian honey from different flora (Mahmoodi-Khaledi et al., 2017; Moloudian et al., 2018). There are few studies on the impact of Iranian honey on neurocognitive disorders (Akouchekian et al., 2018; Jivad et al., 2015). To our knowledge, there is no study regarding the effect of honey on chronic stress conditions, which is very common in various societies. It has been reported that chronic unpredictable mild stress (CUMS) induces learning and memory impairment and also depression (Liu et al., 2014; Willner, 2017; Wu et al., 2017). Meanwhile, It has been shown that CUMS induces a neuronal loss in the hippocampus (Bakhtiarzadeh et al., 2018; Surget et al., 2011; Xue et al., 2017). In the current study, we tried to evaluate the effect of Iranian honey on learning and memory impairment as well as depression, which were induced by CUMS.

\section{Material and methods}

Subject and experimental group

Sixty adults' male Wistar rats, weighing 230-260g (purchased from Isfahan University of Medical Sciences, School of Pharmacy and Pharmaceutical Sciences, Isfahan, Iran) were used in this study. Animals maintained in groups of four per cage under 12h light/ dark cycles with free access to food and water. All experiments were executed in compliance with the $\mathrm{NIH}$ guidelines for the care and use of laboratory animals (National Institutes of Health Publication No. 85-23, revised 2010). Procedures were approved by Isfahan University of Medical Sciences Committee of Ethics in Research (IR.MUI.RESEARCH.REC.1398.300). Animals randomly divided into the following groups: control (1, 2 and 3) groups: animals that received water (as a vehicle) or honey ( 0.2 or $2 \mathrm{~g} / \mathrm{kg} /$ day- orally) until the euthanasia after 46 days of treatment. CUMS (4, 5 and 6) groups: animals that received water or honey ( 0.2 or $2 \mathrm{~g} / \mathrm{kg} /$ day- orally) from 10 days before the onset of the CUMS procedure, which was lasted for 28 consecutive days and continued until the euthanasia (Abdulmajeed et al., 2016; Al-Rahbi et al., 2014b; Arabmoazzen and Sarkaki, 2015; Najafi et al., 2011). The animals were decapitated after performing the Morris water maze (MVM) test and sucrose performance test (SPT). Hippocampus and whole brain samples were collected for further biochemical and histological analysis, respectively. Adrenal glands were gathered for further analysis of weight changes in different groups (Figure $1)$.

\section{Preparation of honey for administration}

Honey was obtained from Dehdar- Taleqan, Alborz province. Regarding the previous study (Guler et al., 2007), the physiochemical properties including proline, 
free acidity and electrical conductivity of the honey were measured according to the national Iranian standard No. 92 (evaluated by Hourtash laboratory). Honey ( 0.2 or $2 \mathrm{~g} / \mathrm{kg}$ ), freshly diluted in water was administrated by gavage ones a day for 46 days in different experimental groups (Abdulmajeed et al., 2016; Al-Rahbi et al., 2014b; Arabmoazzen and Sarkaki, 2015; Najafi et al., 2011).

\section{CUMS procedure}

Rats in CUMS groups were subjected to different mild stressors for 28 days (Borges Filho et al., 2016; Grippo et al., 2005; Liu et al., 2014; Wu et al., 2017). The procedure of CUMS was performed according to previous studies with some modifications (Borges Filho et al., 2016; Grippo et al., 2005; Liu et al., 2014; Wu et al., 2017). In brief, the procedure consisted of the following stressors: 1- water deprivation (10-12h); 2- food deprivation (18h); 3- overnight illumination; 4- cage tilt $40^{\circ}$ (4h); 5 - wet bedding ( $18 \mathrm{~h}, 300 \mathrm{ml}$ of water was added to $300 \mathrm{~g}$ sawdust bedding); 6- clipping the tail (the upper $1 / 3$ of the tail, $1 \mathrm{~min}$ ) and 7 - physically restraint (45min). In each day, only one stressor was applied to the animals. The stress sequence was changed every week. For this manner, these stressors were scheduled over a one-week period and repeated randomly throughout 4-week of the experiment. Stressors were applied randomly and at any time of the day to be completely unpredictable.

\section{Sucrose performance test}

The SPT is a common test to identify the depression in the animals (Belovicova et al., 2017). This test was accomplished after 28 days of exposure to CUMS. For the adaptation of the animals, before the test, rats were treated with sucrose solution $(1 \% \mathrm{w} / \mathrm{v})$, two bottles containing sucrose solution were placed in each cage for $24 \mathrm{~h}$. On the second day, one bottle of sucrose solution was replaced with tap water. After adaptation, animals were deprived of food and water for $24 \mathrm{~h}$. On the test day, a water bottle and a sucrose solution bottle were placed in each cage for each animal. Rats were free to access the water or sucrose. Each bottle contained a $100 \mathrm{ml}$ solution. The volumes of consumed sucrose solution and water in $24 \mathrm{~h}$ were recorded. The sucrose preference was calculated as: the sucrose preference $(\%)=$ sucrose consumption/ (sucrose consumption+ water consumption) (Liu et al., 2014).

\section{Morris water maze test}

To study the effect of honey supplementation on spatial learning and memory, the MVM test was performed at $29^{\text {th }}$ day of the experiment. The procedure was designed as described previously with some modifications (Liu et al., 2014; Morris, 2015; Sadeghi et al., 2017; Wu et al., 2017). In brief, the cylindrical tank, which was $150 \mathrm{~cm}$ in diameter and $60 \mathrm{~cm}$ in height, was filled with water $\left(24 \pm 1^{\circ} \mathrm{C}\right)$ to a depth of $35 \mathrm{~cm}$ and surrounded by

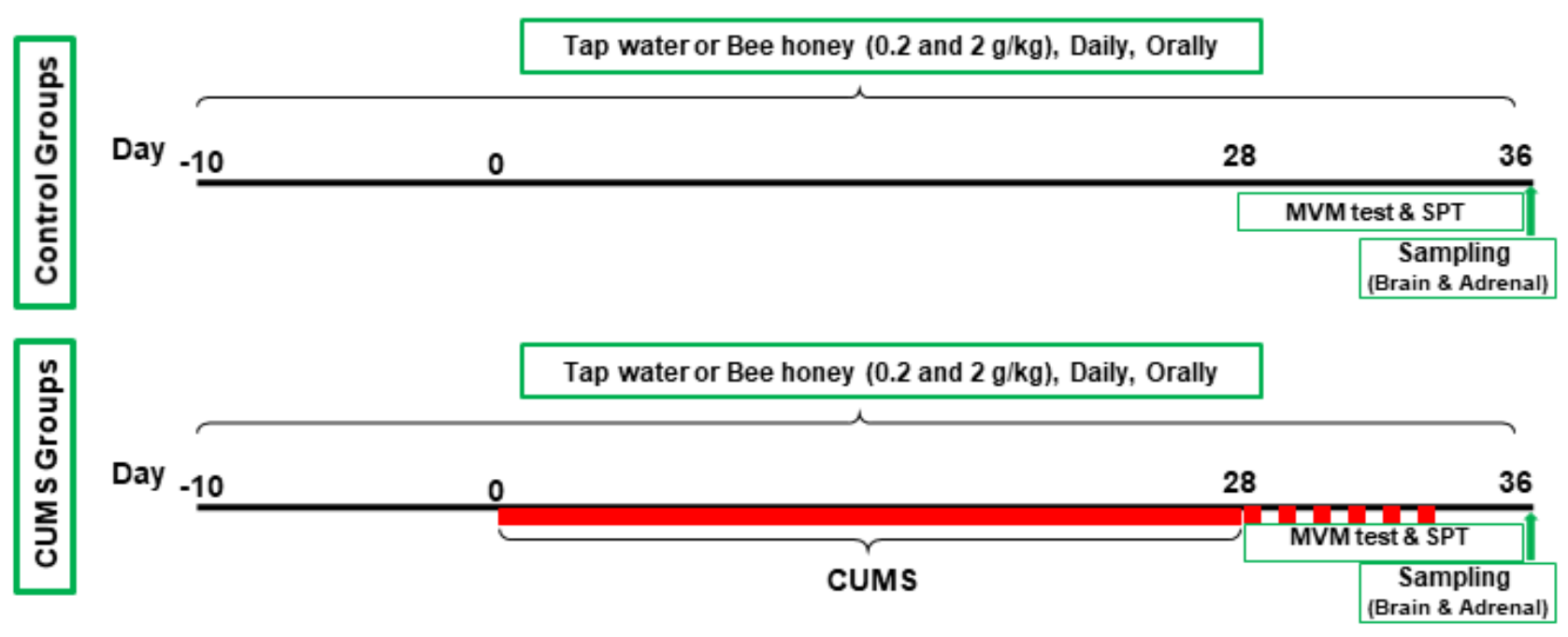

FIGURE 1. Schematic representation of the experimental procedure of the honey pretreatment impact on depression and learning and memory impairment in the CUMS model. The control group received tap water or honey without CUMS induction. Chronic stress was induced for 28 days. Honey administrated (by gavage) to the animals at dose 0.2 or $2 \mathrm{~g} / \mathrm{kg}$ daily for 45 days. MVM test and SPT were assessed to evaluate the spatial learning and memory performance and depression, respectively. When behavioral tests were accomplished, brain samples were collected for further histological and biochemical analysis. Also, the adrenal gland was weighed in different experimental groups. CUMS: chronic unpredictable mild stress, SPT: sucrose performance test, MVM: Morris water maze. 
a variety of extra-maze cues. The test consisted of four consecutive acquisition sessions followed by memory retention (probe trial- day 5). The pool was divided into four quadrants and the round platform was placed in the center of the South- East (target) quadrant $3 \mathrm{~cm}$ underneath the water. Rats were placed into the pool facing the wall and were given 90s to find the hidden platform based on the surrounded cues during each trial. If the rat failed to locate the platform, it was guided to find the platform. The animals were allowed to stay on the platform for 30s. Four acquisition trials were performed in each day. Each animal participated in 16 trials within four days. The time that rats spent to find the hidden platform was measured as the latency. In each trial, the latency and distance of the travel in orbit were tracked by the video camera positioned above the center of the pool and the tracking software was Neuro Vision. To evaluate the memory retention, in a probe trial in which the platform was removed, the rat was placed in the pool for 90s and the time that the animal spent in the target quadrant was recorded.

\section{Tissue sampling}

Hippocampi and adrenal glands were collected from the deep anesthetized and decapitated animals. Hippocampus samples were immediately frozen in liquid nitrogen and then stored at $-80^{\circ} \mathrm{C}$ for further biochemical analysis. The adrenal glands were removed and weighed. For histological analysis, rats were transcardially perfused with phosphate-buffered saline (PBS) followed by $4 \%$ paraformaldehyde. The brains were removed and post-fixed in $4 \%$ paraformaldehyde.

\section{Nissl staining and histological analysis}

A series of $7 \mu \mathrm{m}$ thick coronal sections were obtained from the paraffin- embedded brain samples. Sections from areas between Bregma -2.76 to Bregma 3.24 were collected for the current study (Paxinos and Watson, 2006). Nissl staining was performed to investigate the neuronal density in the CA1 and CA3 regions of the hippocampus. The Nissl staining procedure was explained previously (Yazdi et al., 2020). The CA1 and CA3 regions of the hippocampus were identified under Olympus BX- 51 microscope and Digital images (200x magnification) were captured by DP72 camera. Cell density in the hippocampus was quantified by counting all the cells in each microscopic field. Image J software version $1.5 \mathrm{i}$ was used for cell counting. Three slides per animal and three animals from each group were used for the analysis.

\section{Biochemical analysis}

For analysing the malondialdehyde (MDA) and total antioxidant capacity (TAC) in the hippocampus, the same weight of the tissues in different experimental groups were collected. For MDA assay, the tissues were homogenized with PBS and MDA lysis buffer then centrifuged at $6000 \mathrm{~g}$ for $10 \mathrm{~min}$ and the supernatants were collected. A TBA solution was added and the mixture heated for $60 \mathrm{~min}$ at $95^{\circ} \mathrm{C}$. The absorbance of the supernatant was read at $532 \mathrm{~nm}$ using the spectrophotometer. For TAC assay, the tissues were homogenized by PBS and centrifuged at $12000 \mathrm{~g}$ for $15 \mathrm{~min}$. The supernatant was mixed with TAC buffer, $\mathrm{CU} 2+$ and chromogen solutions. The plate was incubated for $50 \mathrm{~min}$ at room temperature. The absorbance of the specimens was read at $450 \mathrm{~nm}$. The MDA and TAC concentrations were determined by the standard curve and reported as nmol/g tissue. All the procedures were under standard conditions, according to the Kiazist's company instructions on the reagent kits.

\section{Statistical analysis}

GraphPad Prism 5 software was used for statistical analysis. Data are presented as mean \pm SEM. The normal distribution of the data was determined by the Kolmogorov-Smirnov test. To analyze the MVM test, the moving distance and escape latency of 4 trials per day per animal was calculated by repeated measures analysis of the variance (ANOVA) followed by Bonferroni's multiple comparisons post-test. The significant changes between the experimental groups in other tests were determined by one-way ANOVA followed by the Tukey post-test. The $P$ values of less than 0.05 were considered statistically significant.

\section{Results}

\section{Honey physiochemical properties}

The honey contained proline, 569.4mg 100g-1 (standard: <180), free acidity, 13.2 meq kg-1 (standard: $>40$ ) and electrical conductivity, $0.37 \mathrm{mS} \mathrm{cm}-1$ (standard: $>0.8$ ).

Honey supplementation prevented the adrenal weight 


\section{increase in CUMS rats}

The weight of adrenal gland increases in conditions of chronic stress (Ulrich-Lai et al., 2006). To clarify the impact of CUMS and honey supplementation on the adrenal gland, the weight of the adrenal was measured. One-way ANOVA showed that CUMS significantly increased the adrenal weight $[\mathrm{F}(5,38)=$ 16.54, $P<0.0001]$. Tukey post-test showed that CUMS increased the adrenal weight compared to the control group $(P<0.001)$. It also showed that the adrenal weight in the honey treated groups at both doses decreased compared to the CUMS group $(P<0.001)$. However, honey in the control groups had no significant effect on adrenal weight (Figure 2).

Honey supplementation reversed the depression-like behavior of CUMS rats

The SPT is used to evaluate the depressive-like behavior in animals (Belovicova et al., 2017). Oneway ANOVA indicated a main significant change in the sucrose performance $[\mathrm{F}(5,54)=27.42, P<0.0001]$. Tukey post-test showed that after 4 weeks of CUMS exposure, the percentage of sucrose performance was significantly decreased in the stressed rats, compared to the control $(P<0.001$, Figure 3$)$. Tukey post-test also showed that honey alone at both doses had no impact on sucrose intake. Chronic and daily treatment with honey, significantly increased the amount of sucrose performance compared to the stressed animals $(P<0.001)$. These data showed that honey supplementation could restore the depression, which is induced by chronic stress.

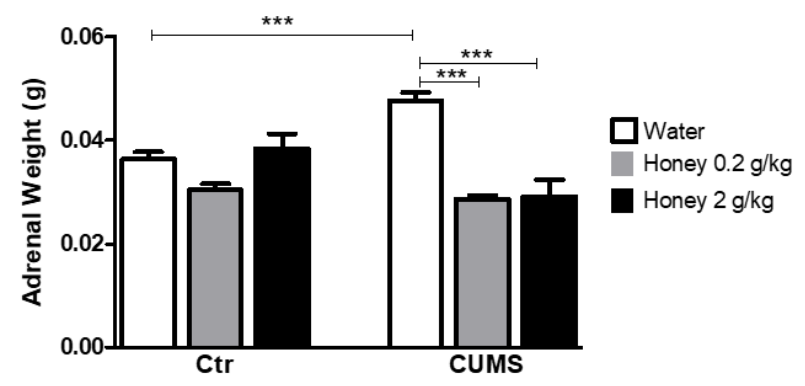

FIGURE 2. Adrenal weight increased due to CUMS induction which is revealed the effectiveness of the chronic stress. Meanwhile, honey administration at both doses significantly prevented adrenal weight elevation in stressed animals. Ctr: control group, CUMS: chronic unpredictable mild stress group. Data are expressed as mean \pm SEM and were analyzed by one-way ANOVA followed by Tukey posttest, ${ }^{* * *} \mathrm{P}<0.001$.
Honey supplementation improved spatial learning and memory impairment in CUMS rats

Figures $4 \mathrm{~A}$ and $\mathrm{B}$ show the moving distance of the animals in the tank and escape latency, respectively. In all groups, the trend of learning became progressively shorter across training sessions. In the spatial cognitive ability test, training days in moving distance $[\mathrm{F}(3,162)=$ 87.18, $P<0.0001]$ and escape latency $[\mathrm{F}(3,162)=70.85$, $P<0.0001]$ parameters, showed significant effect on decreasing learning deficits induced by CUMS. Also, treatment with honey in moving distance $[\mathrm{F}(5,54)=$ 20.12, $P<0.0001]$ and escape latency $[\mathrm{F}(5,54)=8.26$, $P<0.0001]$ parameters, showed significant impact on attenuating the learning problems induced by CUMS. However, there was no significant effect of training days and treatment factors interaction on moving distance $[\mathrm{F}(15,162)=1.29, \quad P=0.2111]$ and escape latency $[\mathrm{F}(15,162)=1.13, P=0.33]$ parameters. Also, Bonferroni multiple comparison showed that the animals in the CUMS group had a significantly longer moving distance and escape latency compared to the control groups (moving distance: $P<0.05$ at day 1 and $P<0.001$ at days 2, 3 and 4; escape latency: $P<0.01$ and $P<0.05$ at second and third days, respectively), which is due to the learning impairment induced by CUMS. Data analysis showed a significant decrease in moving distance in honey treated group (dose $2 \mathrm{~g} / \mathrm{kg})$ in all the training days $(P<0.01$ at day 1 and $P<0.001$ at days 2, 3 and 4). Also, on the third day honey, at a lower dose significantly decreased the moving distance $(P<0.01$, Figure $4 \mathrm{~A})$.

Meanwhile, latency to find the hidden platform significantly reduced by honey administration (dose $2 \mathrm{~g} /$

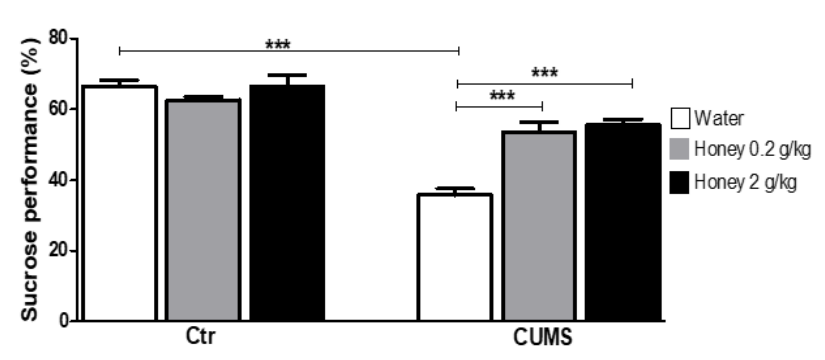

FIGURE 3. Effect of honey administration on depression induced by CUMS. Percentage of sucrose consumption, as an index of depression, significantly decreased in the CUMS group compared to control. However, honey administration significantly increased the tendency of the animals to the sweet drink. Ctr: control group, CUMS: chronic unpredictable mild stress group. Data are expressed as mean \pm SEM and were analyzed by one-way ANOVA followed by Tukey posttest, ${ }^{* * *} \mathrm{P}<0.001$. 

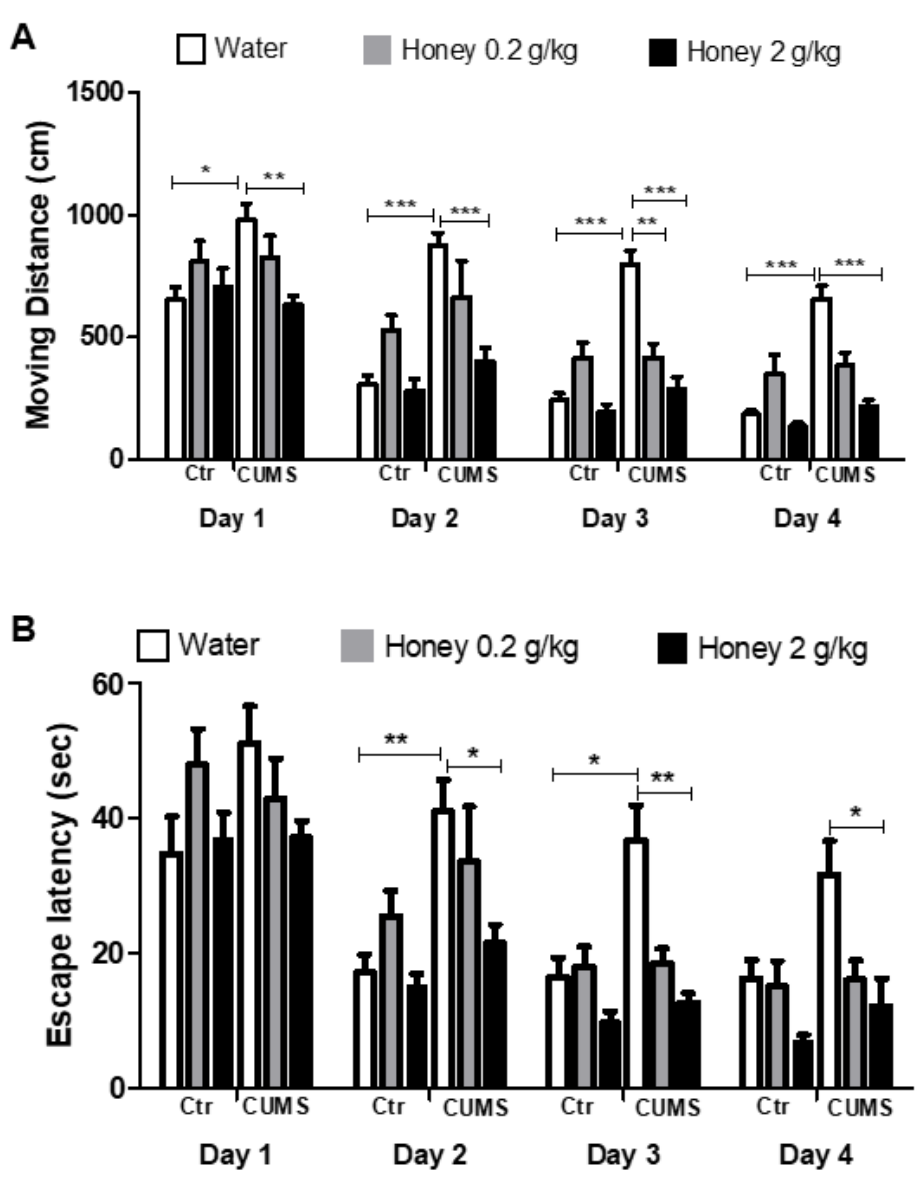

FIGURE 4. Effect of honey administration on spatial learning impairment induced by CUMS. Morris water maze test was done to evaluate the impact of honey on spatial learning performance. (A) Average travel distance and (B) Escape latency were compared in the different experimental groups. Ctr: control group, CUMS: chronic unpredictable mild stress group. Data are expressed as means \pm SEM and calculated by repeated measures analysis of the variance (ANOVA) followed by Bonferroni's multiple comparisons posttest, ${ }^{*} P<0.05,{ }^{* *} P<0.01,{ }^{* * *} P<0.001$.
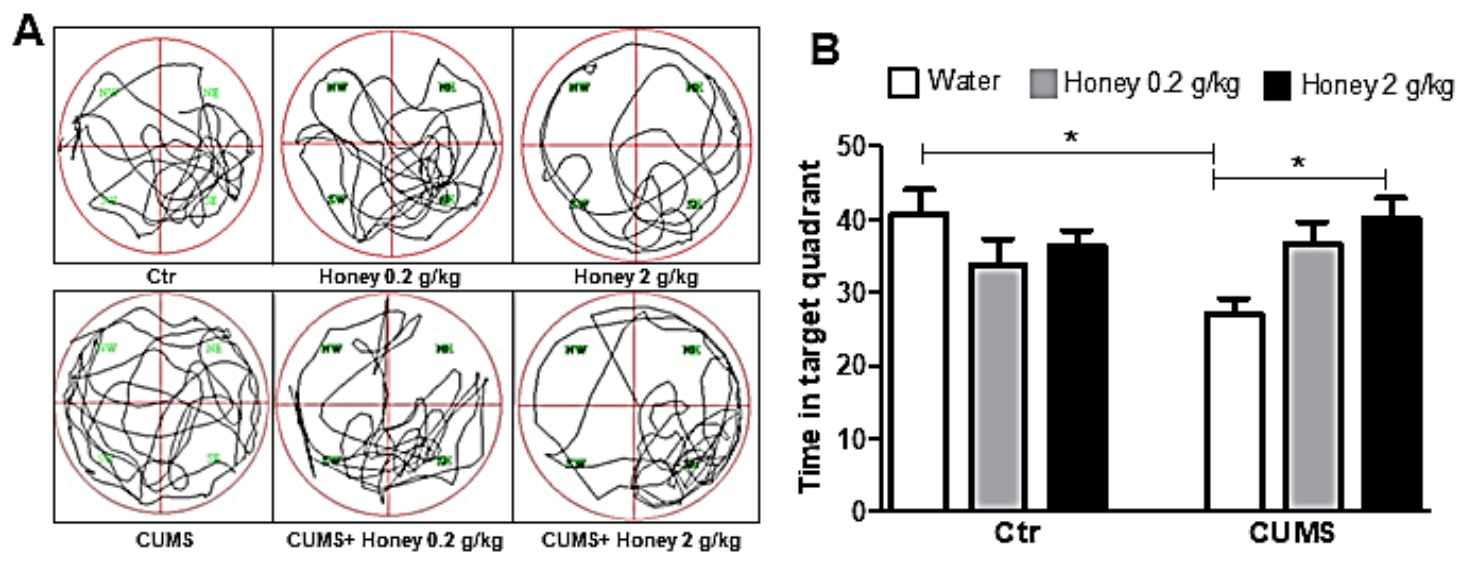

FIGURE 5. Effect of honey treatment on memory improvement in CUMS induced animals. (A) Animal travel orbit in the probe test (B) Analysis of the probe test data indicated that honey at the higher dose $(2 \mathrm{~g} / \mathrm{kg})$ significantly increased the time spent in the target quadrant compared to the CUMS group. Ctr: control group, CUMS: chronic unpredictable mild stress group. Data are expressed as mean \pm SEM and were analyzed by one-way ANOVA followed by Tukey posttest, ${ }^{*} P<0.05$. 
$\mathrm{kg})$ at second $(P<0.05)$, third $(P<0.01)$ and forth $(P<0.05)$ days of the training trial (Figure $4 \mathrm{~B}$ ). To evaluate the spatial memory performance, the platform was removed at day 5 of the test, and the rat was placed in the pool for 90s. The time spent in the target quadrant was recorded for further analysis. Our results showed a significant decrease $(P<0.05)$ in time spent in the target quadrant in stressed rats that is a result of memory deficit induced by CUMS. Conversely, honey supplementation at dose $2 \mathrm{~g} / \mathrm{kg}$ significantly enhanced $(P<0.05)$ the time spent in removed platform quadrant compared to the CUMS group. Data indicate that honey prevented memory impairment in stressed animals (Figure 5).

\section{Honey supplementation ameliorated the neuronal loss} in the hippocampus induced by CUMS

Neuronal damage occurs in the hippocampus under chronic stress (Bakhtiarzadeh et al., 2018; Surget et al., 2011; Xue et al., 2017). The number of neurons in CA1 and CA3 of the hippocampus was counted in the Nissl stained sections. Consistent with previous reports, one-way ANOVA, [CA1: $\mathrm{F}(5,42)=4.85, P=0.001$; CA3: $\mathrm{F}(5,42)=10.57, P<0.0001]$ with Tukey post-test showed a significant decrease in cell number in both CA1 $(P<0.001)$ and CA3 $(P<0.001)$ regions of the hippocampus in CUMS induced animals compared to the control group. Tukey post-test also showed that neuronal death significantly attenuated in the honey treated animals at dose $2 \mathrm{~g} / \mathrm{kg}$ in both CA1 and CA3 regions $(P<0.01$ in $\mathrm{CA} 1$ and $P<0.001$ in CA3), compared to the CUMS group. However, honey at dose $0.2 \mathrm{~g} / \mathrm{kg}$ had a protective effect just in CA1 region $(P<0.05$, Figure 6).

Honey supplementation decreased the MDA level in the hippocampus of the stressed animals but had no effect on TAC level

Evaluation of the level of MDA and TAC in the hippocampus showed an increase in MDA and decrease in TAC level in stressed animals compared to control $(P<0.05)$. Honey treatment at both doses reduced MDA level in stressed group to that of the control group; however, the changes were not significant compared to stress group (Figure 7A). Meanwhile, honey at dose $0.2 \mathrm{~g} / \mathrm{kg}$ in stressed treated group increased the TAC level in the hippocampus while it wasn't significantly (Figure 7B).

\section{Discussion}

Previous reports have shown the relationship between chronic stress and hippocampal atrophy (Krugers et al., 2010; Price and Duman, 2020; Tyrtyshnaia et al., 2019). Various mechanisms are behind the hippocampal neuronal loss induced by CUMS, such as oxidative stress and related inflammation, insulin signaling pathway, norepinephrine, some other hormones and various neurotransmitters (Espinosa-Garcia et al., 2017; Finlay et al., 1995; Latt et al., 2018; Mehta et al., 2017b; Mora et al., 2012; Natarajan et al., 2017). In addition, the hypothalamic-pituitary-adrenal axis is the other pathway that is highly activated by the chronic stress (Mohammadi et al., 2014; Surget et al., 2011; Yang et al., 2017). Over-exposure of the glucocorticoids in the animals has been implicated in the hippocampal neuronal loss (Latt et al., 2018; MacMaster and Kusumakar, 2004). In the present study, behavioral, histological and biochemical approaches were applied to investigate the protective effect of honey on CUMS induced memory deficits and depression. To evaluate the induction of chronic stress in the animals, the adrenal glands were weighed. Previous studies showed that adrenal gland weight increased under chronic stress (Rostamkhani et al., 2012; Ulrich-Lai et al., 2006). Also, our data demonstrated that adrenal weight in stressed rats increased significantly compared to the control group. However, honey protected the adrenal gland from weight elevation. This result might be in line with the previous study, which showed that administration of antioxidants after the establishment of the stress in animals decreased the adrenal weight (Airrapetiants et al., 1986). However, further studies are needed to realize the exact underlying mechanism. One of the comorbidities of chronic stress is depression, which can be investigated by the SPT. Reduced sweet solution intake is the index of depression in this test. Meanwhile, CUMS procedure has long been used as a model of depression (Liu et al., 2014; Stemmelin et al., 2010; Willner, 2017; Willner, 1997; Wu et al., 2017). We performed the SPT after four weeks induction of a various range of stress to the animals. Our results demonstrated that honey supplementation at both doses significantly attenuated the depression-like behavior. Previous studies also revealed the antidepressant efficiency of the honey administration (Azman et al., 2015; Sheas et al., 2019). It is reported that chronic 


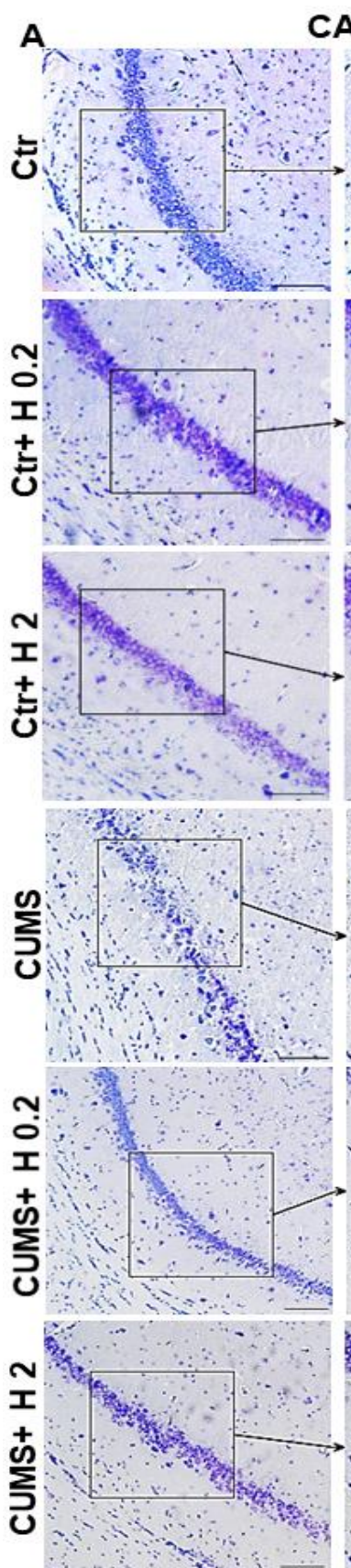

CA1
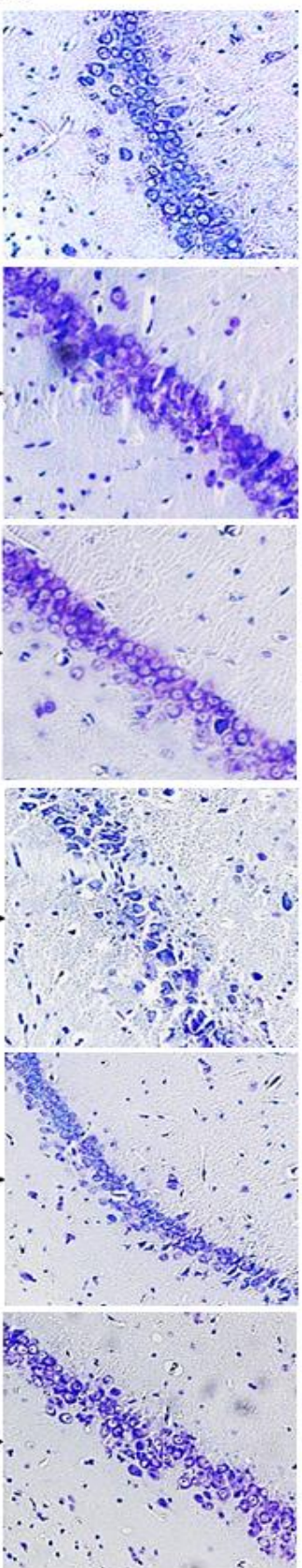

B

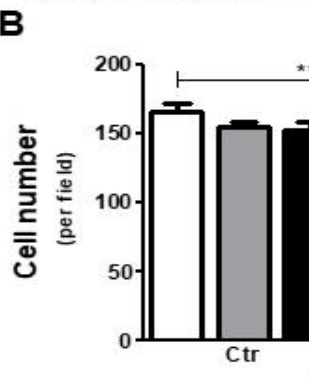

CA1

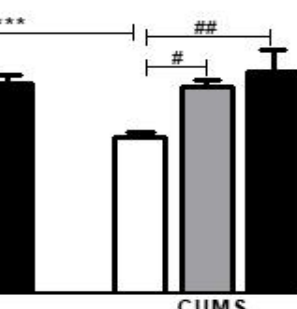

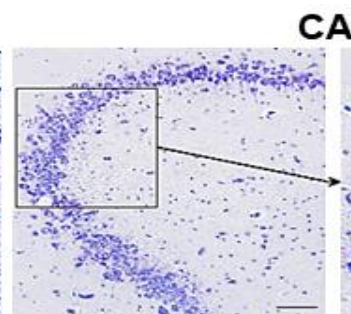

CA3
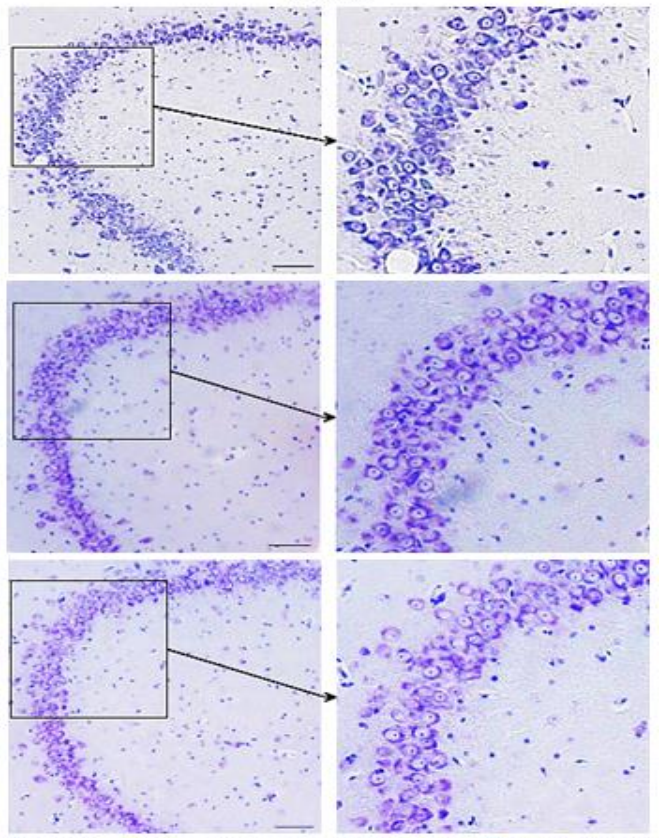

$18790^{\circ}$
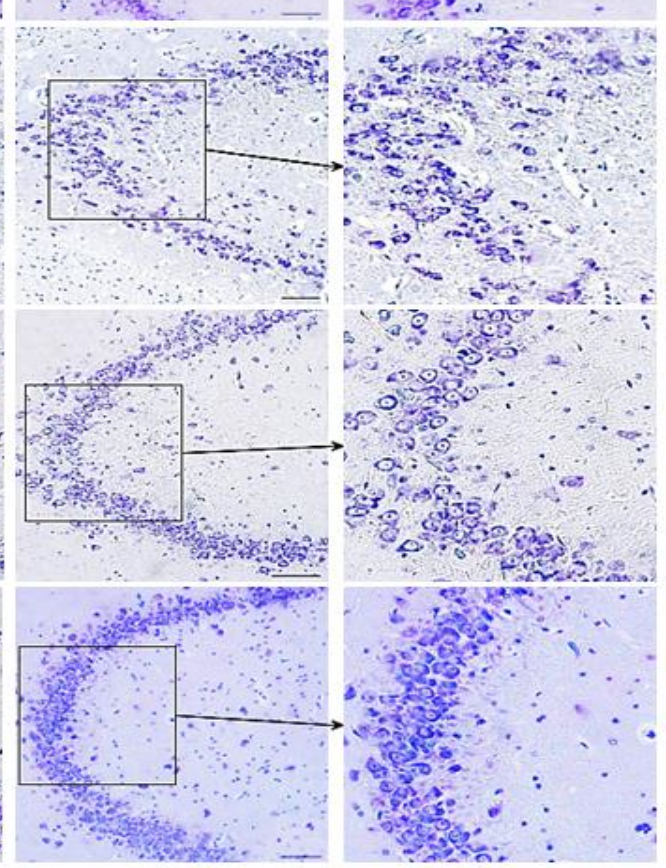

C

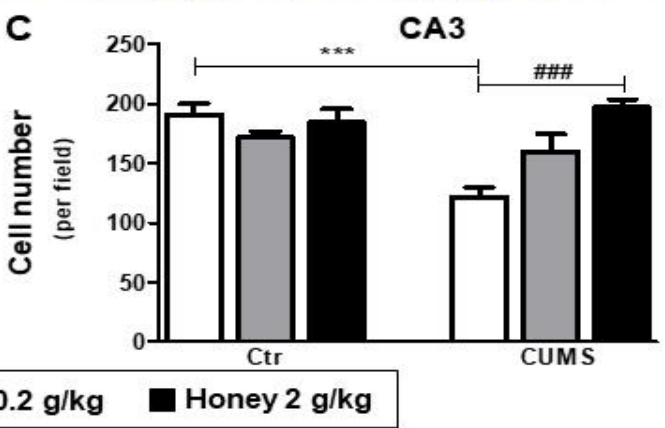

FIGURE 6. Effect of honey administration on neuronal loss in the hippocampus. (A) Nissl staining assessed the amount of cell death in different experimental groups in CA1 and CA3 regions of the hippocampus. (B, C) Quantitative analysis of cell density. Honey at high dose (2g/ $\mathrm{kg}$ ) significantly decreased cell loss in both CA1 and CA3 regions. However, a low dose of honey administration significantly attenuated the neuronal loss in CA1. Ctr: control group, CUMS: chronic unpredictable mild stress group, H: honey. Data are expressed as mean \pm SEM and were analyzed by one-way ANOVA followed by Tukey posttest. Scale bar: $50 \mu \mathrm{m}, \mathrm{n}=3$; ${ }^{\#} P<0.05,{ }^{\#} P<0.01,{ }^{* * *},{ }^{\prime \prime \prime} P<0.001$. 
A

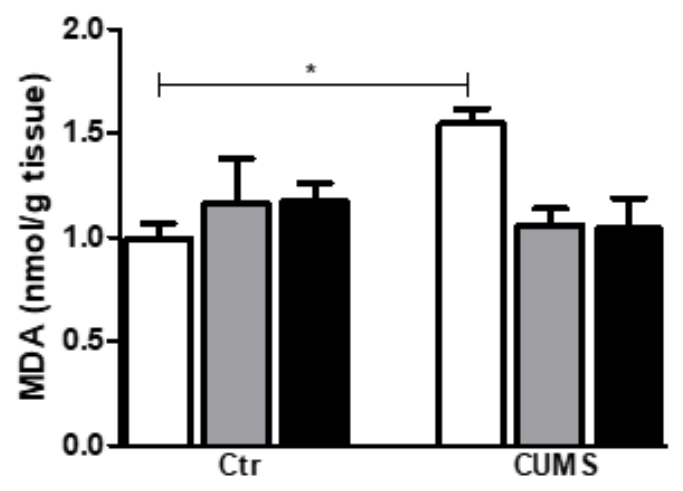

B

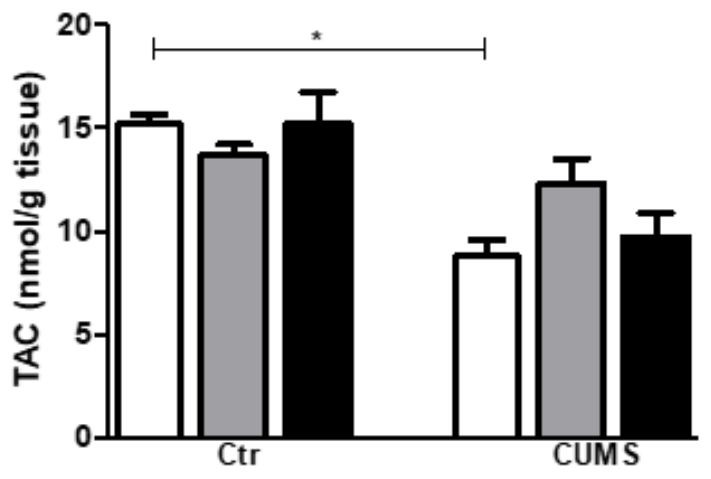

$\square$ water $\square$ Honey $0.2 \mathrm{~g} / \mathrm{kg} \quad \square$ Honey $2 \mathrm{~g} / \mathrm{kg}$

FIGURE 7. Effect of honey administration on the concentration of MDA and TAC in the hippocampus. (A) The concentration of MDA in the hippocampus of CUMS animals significantly elevated compared to the control group. Honey attenuated the lipid peroxidation level by reducing MDA level to that of the control group; however, results were not significant compared to stress group. (B) Biochemical analysis showed that CUMS significantly decreased the TAC level in the hippocampus. Honey at lower dose increased TAC level (not significantly) in CUMS treated animals. Concentration demonstrated as nanomole/g tissue. Ctr: control group, CUMS: chronic unpredictable mild stress group. Data are expressed as mean \pm SEM and were analyzed by one-way ANOVA followed by Tukey posttest. $n=6,{ }^{*} P<0.05$.

stress elevated plasma levels of corticotropin-releasing and adrenocorticotropin hormones, as well as interlukin$1 \beta$, tumor necrosis factor- $\alpha$, interlukin- 6 , kynurenine and decreased serotonin level in the hippocampus. Meanwhile, chronic stress increased indoleamine-2, 3-dioxygenase and caspase 3 as well as 9 activity. However, brain derived neurotrophic factor, nerve growth factor level, and $\mathrm{Na}+/ \mathrm{K}+$ ATPase activity strongly decreased in the hippocampus of the depressed animals, which was induced by CUMS. Treatment with chrysin, as a flavonoid which is found in honey, modified these alterations occasioned by chronic stress (Borges Filho et al., 2016; Jesse et al., 2015). Also, a recent report has shown pinocembrin, a flavonoid isolated from honey, mitigated depressive-like behaviors via a decrease in the concentration of reactive oxygen species and MDA, but increased the superoxide dismutase activity, suggesting that it could protect oxidative stress in CUMS mice. Also, pinocembrin inhibited cell apoptosis and regulated inflammatory factors expression such as interlukin-10, transforming growth factor- $\beta$ in the hippocampus of CUMS animals. Moreover, CUMS inhibited the Nrf2/HO-1 signaling pathway and activated the phosphorylation of NF- $\mathrm{kB}$ which were converted by pinocembrin (Wang et al., 2020). Therefore, the antidepressant-like effect of honey administration in the current study might be due to the regulation of above mentioned neurochemical factors. More analysis is needed to clarify the exact underlying mechanism. Many studies displayed the negative impact of chronic stress on learning and memory. Morris water maze test is one of the most widely used tests as hippocampaldependent spatial learning and memory performance (Liu et al., 2014; Wu et al., 2017). In the present study, we found that impairment in both learning and memory performance induced by CUMS was significantly reversed by honey supplementation, which was consistent with previous studies (Abdulmajeed et al., 2016; Arshad et al., 2020; Azman et al., 2015; Azman et al., 2016; Othman et al., 2011). Generally, the evidence indicated that honey supplementation attenuated depression and learning and memory comorbidities induced by CUMS. It has been reported that the hippocampal neurodegeneration is highly related to depression and some cognitive disorders such as learning and memory impairment (Lee et al., 2002; Sapolsky, 2000; Setti et al., 2017). Meanwhile, there is growing evidence that different antidepressant drugs make proliferative and neurogenesis changes in the hippocampus regions (Stemmelin et al., 2008). To characterize the underlying mechanism of the positive effect of honey supplementation, at the next step, we investigated the cell density in the hippocampus. Previous experimental studies have revealed the neurodegeneration in the hippocampus of the animals, which were under chronic stress (Al-Rahbi et al., 2014c; 
Mehrpouya et al., 2015; Surget et al., 2011; Takuma et al., 2012). Our results also showed the neurodegeneration in both CA1 and CA3 regions of the hippocampus in the CUMS group compared to control. Neuroprotection is explained as any activity that conserves neuronal function and structure (Casson et al., 2012). Neuronal loss significantly decreased in the hippocampus of the treated animals. It is reported that honey ingredients have a protective effect on neurons (Jafari Anarkooli et al., 2014; Saad et al., 2015; Takashima et al., 2019). Also, an experiment has been suggested that honey has a positive effect at the neuronal morphometric level (Adli, 2018). In parallel with the previous studies, our results confirmed the neuroprotective effect of honey supplementation. Hippocampal damage induced by chronic stress also occurs due to mitochondrial dysfunction and apoptosis by activating ROS/JNK signaling pathway (Zhang et al., 2020). Effect of honey administration on these mechanisms should be investigated in the future. Meanwhile, oxidative stress pathway is one of the most important mechanisms that may lead to neuronal loss under chronic stress (Manoli et al., 2000; Salim, 2017; Schiavone et al., 2013; Xu et al., 2019; Zhang et al., 2020). In the next part of the study, we investigated the effect of honey supplementation on two oxidative stress markers, malondialdehyde and total antioxidant capacity. MDA is the most commonly used lipid marker of oxidative stress. The other common assay is the TAC, which represents changes in small molecules and protein antioxidant based capacity (Marrocco et al., 2017; Popović et al., 2019). Several studies showed the MDA and TAC changes in the hippocampus in chronic stress circumstances (Che et al., 2015; Hu et al., 2016; Jin et al., 2015; Mehta et al., 2017a). Our results also showed the increase and decrease of MDA and TAC in the hippocampus of the stressed rats, respectively. Honey at both doses attenuated lipid peroxidation by decreasing the MDA level of the hippocampus to that of the control group. Meanwhile, honey at dose $0.2 \mathrm{~g} / \mathrm{kg}$ in stressed treated group increased the TAC level in the hippocampus while it wasn't significantly. Oxidative stress occurs due to the imbalance between reactive oxygen species formation and enzymatic or non-enzymatic antioxidants (Marrocco et al., 2017). The influence of the honey antioxidants on the oxidative stress pathway might also be through some different oxidative species or biomarkers. A previous study by Azman and colleague (2016) showed that honey reduced the brain oxidative stress through the effect on MDA, protein carbonyl and superoxide dismutasebut not via glutathione peroxidase, glutathione reductase, catalase and TAC.

According to the result of the current study, honey supplementation diminished learning and memory impairment and depression that might be mediated via its neuroprotective activity. It seems that the reduction in the neuronal loss might be due to the attenuation in lipid peroxidation induced by honey supplementation in the hippocampus. However, in the future, investigation of other biomarkers of the oxidative pathway, such as the enzymatic or non- enzymatic antioxidants, DNA/RNA damage markers, protein oxidation or nitration markers could help us to find more about the underlying mechanisms of the honey supplementation on neuroprotection.

\section{Conclusion}

In conclusion, learning and memory impairment and also depression which are two major comorbidities of the chronic stress, attenuated by Iranian honey supplementation. It seems that these findings are partly mediated via the honey neuroprotective activity in the hippocampus tissue of the stressed animals that might be due to a reduction in lipid peroxidation activity. Further studies are needed to find out the other related mechanisms of honey supplementation on the neuronal cells in the hippocampus.

\section{Acknowledgment}

This work was supported by the Isfahan University of Medical Sciences, Isfahan, Iran [grant number 198028].

\section{Conflict of interest}

None.

\section{References}

Abdulmajeed WI, Sulieman HB, Zubayr MO, Imam A, Amin A, Biliaminu SA, et al. Honey prevents neurobehavioural deficit and oxidative stress induced by lead acetate exposure in male wistar rats-a preliminary study. Metab Brain Dis 2016; 31: 37-44. https://doi.org/10.1007/s11011015-9733-6

Adli DS. Morphometric study of hippocampal CA1 pyramidal neurons after tualang honey administration. Malaysian 
Journal of Microscopy 2018; 14.

Airrapetiants MG, Levshina IP, Guliaeva NV. Therapeutic action of an antioxidant in chronic emotional-pain stress in the rat. Zh Vyssh Nerv Deiat Im I P Pavlova 1986; 36 : 554-60.

Akanmu MA, Olowookere TA, Atunwa SA, Ibrahim BO, Lamidi OF, Adams PA, et al. Neuropharmacological effects of Nigerian honey in mice. Afr J Tradit Complement Altern Med 2011; 8. https://doi.org/10.4314/ajtcam. v8i3.65285

Akouchekian S, Omranifard V, Maracy MR, Pedram A, Zefreh AA. Akouchekian S, Omranifard V, Maracy MR, Pedram A, Zefreh AA. Efficacy of herbal combination of sedge, saffron, and Astragalus honey on major neurocognitive disorder. J Res Med Sci 2018; 23. https://doi.org/10.4103/ jrms.JRMS_949_17

Al-Rahbi B, Zakaria R, Othman Z, Hassan A, Ahmad AH. Enhancement of BDNF concentration and restoration of the hypothalamic-pituitary-adrenal axis accompany reduced depressive-like behaviour in stressed ovariectomised rats treated with either Tualang honey or estrogen. Sci World J 2014a; 2014. https://doi.org/10.1155/2014/310821

Al-Rahbi B, Zakaria R, Othman Z, Hassan A, Ahmad AH. Protective effects of Tualang honey against oxidative stress and anxiety-like behaviour in stressed ovariectomized rats. Int Sch Res Notices 2014b; 2014. https://doi. org/10.1155/2014/521065

Al-Rahbi B, Zakaria R, Othman Z, Hassan A, Ismail ZI, Muthuraju S. Tualang honey supplement improves memory performance and hippocampal morphology in stressed ovariectomized rats. Acta Histochemica 2014c; 116: 7988. https://doi.org/10.1016/j.acthis.2013.05.004

Ali AM, Hendawy AO. Bee honey as a potentially effective treatment for depression: a review of clinical and preclinical findings. JOJ Nurse Health Care 2018; 9: 555764. https:// doi.org/10.19080/JOJNHC.2018.09.555764

Arabmoazzen S, Sarkaki A. Antidiabetic effect of honey feeding in noise induced hyperglycemic rat: involvement of oxidative stress. Iran J Basic Med Sci 2015; 18: 745.

Arshad NA, Lin TS, Yahaya MF. Stingless bee honey reduces anxiety and improves memory of the metabolic diseaseinduced rats. CNS Neurol Disord Drug Targets 2020. https://doi.org/10.2174/18715273196662001171051 33

Azman KF, Zakaria R, AbdAziz C, Othman Z, Al-Rahbi B. Tualang honey improves memory performance and decreases depressive-like behavior in rats exposed to loud noise stress. Noise Health 2015; 17: 83. https://doi. org/10.4103/1463-1741.153388

Azman KF, Zakaria R, Abdul Aziz CB, Othman Z. Tualang honey attenuates noise stress-induced memory deficits in aged rats. Oxid Med Cell Longev 2016; 2016. https://doi. org/10.1155/2016/1549158

Bakhtiarzadeh F, Nahavandi A, Goudarzi M, Shirvalilou S, Rakhshan K, Niknazar S. Axonal transport proteins and depressive like behavior, following chronic unpredictable mild stress in male rat. Physiol Behav 2018; 194: 9-14. https://doi.org/10.1016/j.physbeh.2018.04.029

Baluchnejadmojarad T, Roghani M, Kamran M, Karimi N. The effect of alpha-lipoic acid on learning and memory deficit in a rat model of temporal lobe epilepsy. Basic Clin Neurosci 2012; 3: 58-66.

Belovicova K, Bogi E, Csatlosova K, Dubovicky M. Animal tests for anxiety-like and depression-like behavior in rats. Interdiscip Toxicol 2017; 10: 40-3. https://doi.org/10.1515/ intox-2017-0006

Borges Filho C, Jesse CR, Donato F, Del Fabbro L, de Gomes MG, Goes AT, et al. Neurochemical factors associated with the antidepressant-like effect of flavonoid chrysin in chronically stressed mice. Eur J Pharmacol 2016; 791: 28496. https://doi.org/10.1016/j.ejphar.2016.09.005

Braak H, Braak E. Neuropathological stageing of Alzheimerrelated changes. Acta Neuropathol 1991; 82: 239-59. https://doi.org/10.1007/BF00308809

Casson RJ, Chidlow G, Ebneter A, Wood JP, Crowston J, Goldberg I. Translational neuroprotection research in glaucoma: a review of definitions and principles. Clin Exp Ophthalmol 2012; 40: 350-7. https://doi.org/10.1111/ j.1442-9071.2011.02563.x

Che Y, Zhou Z, Shu Y, Zhai C, Zhu Y, Gong S, et al. Chronic unpredictable stress impairs endogenous antioxidant defense in rat brain. Neurosci lett 2015; 584: 208-13. https://doi.org/10.1016/j.neulet.2014.10.031

Chen C, Zhang H, Xu H, Zheng Y, Wu T, Lian Y. Ginsenoside $\mathrm{Rb} 1$ ameliorates cisplatin-induced learning and memory impairments. J Ginseng Res 2019; 43: 499-507. https://doi. org/10.1016/j.jgr.2017.07.009

Chepulis LM, Starkey NJ, Waas JR, Molan PC. The effects of long-term honey, sucrose or sugar-free diets on memory and anxiety in rats. Physiol Behav 2009; 97: 359-68. https://doi.org/10.1016/j.physbeh.2009.03.001

Devan BD, Goad EH, Petri HL. Dissociation of hippocampal and striatal contributions to spatial navigation in the water 
maze. Neurobiol Learn Mem 1996; 66: 305-23. https://doi. org/10.1006/nlme.1996.0072

dos Santos Junior JG, do Monte FH, Blanco MM, Lanziotti VM, Maia FD, de Almeida Leal LK. Cognitive enhancement in aged rats after chronic administration of Equisetum arvense L. with demonstrated antioxidant properties in vitro. Pharmacol Biochem Behav 2005; 81: 593-600. https://doi.org/10.1016/j.pbb.2005.04.012

Espinosa-Garcia C, Sayeed I, Yousuf S, Atif F, Sergeeva EG, Neigh GN, et al. Stress primes microglial polarization after global ischemia: therapeutic potential of progesterone. Brain Behav Immun 2017; 66: 177-92. https://doi. org/10.1016/j.bbi.2017.06.012

Farajdokht F, Nahavandi A, Soleimani M. Effects of dalteparin on structure of hippocampal neurons of rats in chronic stress. Basic Clin Neurosci 2012; 3: 32-7.

Finlay JM, Zigmond MJ, Abercrombie ED. Increased dopamine and norepinephrine release in medial prefrontal cortex induced by acute and chronic stress: effects of diazepam. Neuroscience 1995; 64: 619-28. https://doi. org/10.1016/0306-4522(94)00331-X

Ganji A, Salehi I, Nazari M, Taheri M, Komaki A. Effects of Hypericum scabrum extract on learning and memory and oxidant/antioxidant status in rats fed a long-term highfat diet. Metab Brain Dis 2017; 32: 1255-65. https://doi. org/10.1007/s11011-017-0022-4

Gheldof N, Engeseth NJ. Antioxidant capacity of honeys from various floral sources based on the determination of oxygen radical absorbance capacity and inhibition of in vitro lipoprotein oxidation in human serum samples. JAgric Food Chem 2002; 50: 3050-5. https://doi.org/10.1021/ jf0114637

Grippo AJ, Sullivan NR, Damjanoska KJ, Crane JW, Carrasco GA, Shi J, et al. Chronic mild stress induces behavioral and physiological changes, and may alter serotonin 1A receptor function, in male and cycling female rats. Psychopharmacology 2005; 179: 769-80. https://doi. org/10.1007/s00213-004-2103-4

Guler A, Bakan A, Nisbet C, Yavuz O. Determination of important biochemical properties of honey to discriminate pure and adulterated honey with sucrose (Saccharum officinarum L.) syrup. Food Chem 2007; 105: 1119-25. https://doi.org/10.1016/j.foodchem.2007.02.024

$\mathrm{Hu}$ M, Zou W, Wang CY, Chen X, Tan HY, Zeng HY, et al. Hydrogen sulfide protects against chronic unpredictable mild stress-induced oxidative stress in hippocampus by upregulation of BDNF-TrkB pathway.
Oxid Med Cell Longev 2016; 2016. https://doi. org/10.1155/2016/2153745

Ikeda-Douglas CJ, Zicker SC, Estrada J, Jewell DE, Milgram NW. Prior experience, antioxidants, and mitochondrial cofactors improve cognitive function in aged beagles. Vet Therapeut 2004; 5: 5-16.

Jafari Anarkooli I, Barzegar Ganji H, Pourheidar M. The protective effects of insulin and natural honey against hippocampal cell death in streptozotocin-induced diabetic rats. J Diabetes Res 2014; 2014. https://doi. org/10.1155/2014/491571

Jesse CR, Donato F, Giacomeli R, Del Fabbro L, da Silva Antunes M, De Gomes MG, et al. Chronic unpredictable mild stress decreases BDNF and NGF levels and $\mathrm{Na}+, \mathrm{K}+$ ATPase activity in the hippocampus and prefrontal cortex of mice: Antidepressant effect of chrysin. Neuroscience 2015; 289: 367-380. https://doi.org/10.1016/j. neuroscience.2014.12.048

Jin P, Yu HL, Zhang F, Quan ZS. Antidepressant-like effects of oleoylethanolamide in a mouse model of chronic unpredictable mild stress. Pharmacol Biochem Behav 2015; 133: 146-54. https://doi.org/10.1016/j. pbb.2015.04.001

Jivad N, Zare-Hassanabadi N, Azizi M. Effect of combination of honey, saffron (Crocus sativus L.) and sedge (Cyperus rotundus L.) on cognitive dysfunction in patients with Alzheimer's disease. Adv Herbal Med 2015; 1: 11-6.

Kim EJ, Pellman B, Kim JJ. Stress effects on the hippocampus: a critical review. Learn Mem 2015; 22: 411-6. https://doi. org/10.1101/lm.037291.114

Kolosova NG, Shcheglova TV, Sergeeva SV, Loskutova LV. Long-term antioxidant supplementation attenuates oxidative stress markers and cognitive deficits in senescent-accelerated OXYS rats. Neurobiol Aging 2006; 27: 1289-97. https://doi.org/10.1016/j. neurobiolaging.2005.07.022

Krugers HJ, Lucassen P, Karst H, Joëls M. Chronic stress effects on hippocampal structure and synaptic function: relevance for depression and normalization by antiglucocorticoid treatment. Front Synaptic Neurosci 2010; 2: 24. https://doi.org/10.3389/fnsyn.2010.00024

Latt HM, Matsushita H, Morino M, Koga Y, Michiue $\mathrm{H}$, Nishiki $\mathrm{T}$, et al. Oxytocin inhibits corticosteroneinduced apoptosis in primary hippocampal neurons. Neuroscience 2018; 379: 383-9. https://doi.org/10.1016/j. neuroscience.2018.03.025 
Lee AL, Ogle WO, Sapolsky RM. Stress and depression: possible links to neuron death in the hippocampus. Bipolar Disord 2002; 4: 117-28. https://doi.org/10.1034/j.13995618.2002.01144.x

Lindau M, Almkvist O, Mohammed AH. Effects of stress on learning and memory. In: Stress: Concepts, cognition, emotion, and behavior. Academic Press, 2016, p. 153-160. https://doi.org/10.1016/B978-0-12-8009512.00018-2

Liu D, Wang Z, Gao Z, Xie K, Zhang Q, Jiang H, et al. Effects of curcumin on learning and memory deficits, BDNF, and ERK protein expression in rats exposed to chronic unpredictable stress. Behav Brain Res 2014; 271: 116-21. https://doi.org/10.1016/j.bbr.2014.05.068

MacMaster FP, Kusumakar V. Hippocampal volume in early onset depression. BMC Med 2004; 2: 2. https://doi. org/10.1186/1741-7015-2-2

Mahmoodi-Khaledi E, Lozano-Sánchez J, Bakhouche A, Habibi-Rezaei M, Sadeghian I, Segura-Carretero A. Physicochemical properties and biological activities of honeys from different geographical and botanical origins in Iran. Eur Food Res Technol 2017; 243: 1019-30. https:// doi.org/10.1007/s00217-016-2811-0

Manoli LP, Gamaro GD, Silveira PP, Dalmaz C. Effect of chronic variate stress on thiobarbituric-acid reactive species and on total radical-trapping potential in distinct regions of rat brain. Neurochem Res 2000; 25: 915-21. https://doi.org/10.1023/A:1007592022575

Marrocco I, Altieri F, Peluso I. Measurement and clinical significance of biomarkers of oxidative stress in humans. Oxid Med Cell Longev 2017; 2017. https://doi. org/10.1155/2017/6501046

Maurya S, Kushwaha AK, Singh S, Singh G. An overview on antioxidative potential of honey from different flora and geographical origins. Indian J Nat Prod Resour 2014; 5: 9-19.

Mehrpouya S, Nahavandi A, Khojasteh F, Soleimani M, Ahmadi M, Barati M. Iron administration prevents BDNF decrease and depressive-like behavior following chronic stress. Brain Res 2015; 1596: 79-87. https://doi. org/10.1016/j.brainres.2014.10.057

Mehta V, Parashar A, Udayabanu M. Quercetin prevents chronic unpredictable stress induced behavioral dysfunction in mice by alleviating hippocampal oxidative and inflammatory stress. Physiol Behav 2017a; 171: 69-78. https://doi.org/10.1016/j.physbeh.2017.01.006

Mehta V, Singh TR, Udayabanu M. Quercetin ameliorates chronic unpredicted stress-induced behavioral dysfunction in male Swiss albino mice by modulating hippocampal insulin signaling pathway. Physiol Behav 2017b; 182: 106. https://doi.org/10.1016/j.physbeh.2017.09.019

Mohammadi HS, Goudarzi I, Lashkarbolouki T, Abrari K, Salmani ME. Chronic administration of quercetin prevent spatial learning and memory deficits provoked by chronic stress in rats. Behav Brain Res 2014; 270: 196-205. https:// doi.org/10.1016/j.bbr.2014.05.015

Moloudian H, Abbasian S, Nassiri-Koopaei N, Tahmasbi MR, Alsadat Afzal G, Ahosseini MS, et al. Characterization and classification of iranian honey based on physicochemical properties and antioxidant activities, with chemometrics approach. Iran J Pharm Res 2018; 17: 708.

Mora F, Segovia G, del Arco A, de Blas M, Garrido P. Stress, neurotransmitters, corticosterone and body-brain integration. Brain Res 2012; 1476: 71-85. https://doi. org/10.1016/j.brainres.2011.12.049

Morris RG. The watermaze. In: The Maze Book. New York: Springer, Humana Press 2015, p. 73-92. https://doi. org/10.1007/978-1-4939-2159-1_3

Najafi M, Shaseb E, Ghaffary S, Fakhrju A, Eteraf Oskouei T. Effects of chronic oral administration of natural honey on ischemia/reperfusion-induced arrhythmias in isolated rat heart. Iran J Basic Med Sci 2011; 14: 75-81.

Natarajan R, Forrester L, Chiaia NL, Yamamoto BK. Chronic-stress-induced behavioral changes associated with subregion-selective serotonin cell death in the dorsal raphe. J Neurosci 2017; 37: 6214-23. https://doi.org/10.1523/ JNEUROSCI.3781-16.2017

Noseworthy MD, Bray TM. Effect of oxidative stress on brain damage detected by MRI and in vivo 31P-NMR. Free Radic Biol Med 1998; 24: 942-51. https://doi.org/10.1016/ S0891-5849(97)00383-3

Othman Z, Shafin N, Zakaria R, Hussain NH, Mohammad WM. Improvement in immediate memory after 16 weeks of tualang honey (Agro Mas) supplement in healthy postmenopausal women. Menopause 2011; 18: 1219-24. https://doi.org/10.1097/gme.0b013e31821e2044

Oyefuga OH, Ajani EO, Salau BA, Agboola F, Adebawo OO. Honey consumption and its anti-ageing potency in white Wister albino rats. Sch J Biol Sci 2012; 1: 15-9.

Paxinos G, Watson C. The rat brain in stereotaxic coordinates: hard cover edition. Elsevier, 2006.

Popović N, Stojiljković V, Pejić S, Todorović A, Pavlović I, Gavrilović L, et al. Modulation of hippocampal antioxidant defense system in chronically stressed rats by 
lithium. Oxid Med Cell Longev 2019; 2019. https://doi. org/10.1155/2019/8745376

Price RB, Duman R. Neuroplasticity in cognitive and psychological mechanisms of depression: an integrative model. Mol Psychiatry 2020; 25: 530-43. https://doi. org/10.1038/s41380-019-0615-X

Rostamkhani F, Zardooz H, Zahediasl S, Farrokhi B. Comparison of the effects of acute and chronic psychological stress on metabolic features in rats. J Zhejiang Univ Sci B 2012; 13: 904-12. https://doi.org/10.1631/jzus. B1100383

Saad MA, Salam RM, Kenawy SA, Attia AS. Pinocembrin attenuates hippocampal inflammation, oxidative perturbations and apoptosis in a rat model of global cerebral ischemia reperfusion. Pharmacol Rep 2015; 67: 115-22. https://doi.org/10.1016/j.pharep.2014.08.014

Sadeghi M, Reisi P, Radahmadi M. The effects of CCK-8S on spatial memory and long-term potentiation at CA1 during induction of stress in rats. Iran J Basic Med Sci 2017; 20: 1368.

Salim S. Oxidative stress and the central nervous system. J Pharmacol Exp Ther 2017; 360: 201-5. https://doi. org/10.1124/jpet.116.237503

Sapolsky RM. The possibility of neurotoxicity in the hippocampus in major depression: a primer on neuron death. Biol Psychiatry 2000; 48: 755-65. https://doi. org/10.1016/S0006-3223(00)00971-9

Schiavone S, Jaquet V, Trabace L, Krause KH. Severe life stress and oxidative stress in the brain: from animal models to human pathology. Antioxid Redox Signal 2013; 18: 1475-90. https://doi.org/10.1089/ars.2012.4720

Setti SE, Hunsberger HC, Reed MN. Alterations in hippocampal activity and Alzheimer's disease. Transl Issues Psychol Sci 2017; 3: 348-56. https://doi.org/10.1037/ tps0000124

Sheas MN, Rasool H, Rafique MN, Tariq MR, Muhammad A, Ali K. Exploring the potential of honey and curcumin as antidepressent. Punjab Univ J Zool 2019; 34: 89-95. https:// doi.org/10.17582/journal.pujz/2019.34.1.89.95

Souza-Monteiro JR, Arrifano GP, Queiroz AI, Mello BS, Custódio CS, Macêdo DS, et al. Antidepressant and antiaging effects of acai (euterpe oleracea mart.) in mice. Oxid Med Cell Longev 2019; 2019. https://doi. org/10.1155/2019/3614960

Srivastava KK, Kumar R. Stress, oxidative injury and disease. Indian J Clin Biochem 2015; 30: 3-10. https://doi. org/10.1007/s12291-014-0441-5
Stemmelin J, Canolle B, Roudieres V, Labie C, Fournier J, Cohen C, et al. P. 2. d. 020 Saredutant (SR48968), a NK2 receptor antagonist, blocks chronic stressinduced decrease in neurogenesis in Balb/c mice. Eur Neuropsychopharmacol 2008: S356. https://doi. org/10.1016/S0924-977X(08)70502-9

Stemmelin J, Cohen C, Yalcin I, Keane P, Griebel G. Implication of $\beta 3$-adrenoceptors in the antidepressant-like effects of amibegron using Adrb3 knockout mice in the chronic mild stress. Behav Brain Res 2010; 206: 310-2. https://doi.org/10.1016/j.bbr.2009.09.003

Surget A, Tanti A, Leonardo ED, Laugeray A, Rainer Q, Touma C, et al. Antidepressants recruit new neurons to improve stress response regulation. Mol Psychiatry 2011; 16: 1177-88. https://doi.org/10.1038/mp.2011.48

Takashima M, Ichihara K, Hirata Y. Neuroprotective effects of Brazilian green propolis on oxytosis/ferroptosis in mouse hippocampal HT22 cells. Food Chem Toxicol 2019; 132: 110669. https://doi.org/10.1016/j.fct.2019.110669

Takuma K, Mizoguchi H, Funatsu Y, Kitahara Y, Ibi D, Kamei H, et al. Placental extract improves hippocampal neuronal loss and fear memory impairment resulting from chronic restraint stress in ovariectomized mice. J Pharmacol Sci 2012; 120: 89-97. https://doi.org/10.1254/ jphs.12115FP

Tyrtyshnaia AA, Manzhulo IV, Konovalova SP, Zagliadkina AA. Neuropathic pain causes a decrease in the dendritic tree complexity of hippocampal CA3 pyramidal neurons. Cells Tissues Organs 2019; 208: 89-100. https://doi. org/10.1159/000506812

Ulrich-Lai YM, Figueiredo HF, Ostrander MM, Choi DC, Engeland WC, Herman JP. Chronic stress induces adrenal hyperplasia and hypertrophy in a subregion-specific manner. Am J Physiol Endocrinol Metab 2006; 291: E96573. https://doi.org/10.1152/ajpendo.00070.2006

van Velzen LS, Wijdeveld M, Black CN, van Tol MJ, van der Wee NJ, et al. Oxidative stress and brain morphology in individuals with depression, anxiety and healthy controls. Prog Neuropsychopharmacol Biol Psychiatry 2017; 76: 140-4. https://doi.org/10.1016/j.pnpbp.2017.02.017

Wang W, Zheng L, Xu L, Tu J, Gu X. Pinocembrin mitigates depressive-like behaviors induced by chronic unpredictable mild stress through ameliorating neuroinflammation and apoptosis. Mol Med 2020; 26: 1-11. https://doi. org/10.1186/s10020-020-00179-X

Wang X, Michaelis EK. Selective neuronal vulnerability to oxidative stress in the brain. Front Aging Neurosci 2010; 
2: 12. https://doi.org/10.3389/fnagi.2010.00012

Wang X, Sankarapandian K, Cheng Y, Woo SO, Kwon HW, Perumalsamy $\mathrm{H}$, et al. Relationship between total phenolic contents and biological properties of propolis from 20 different regions in South Korea. BMC Compl Alternative Med 2016; 16: 65. https://doi.org/10.1186/s12906-016$1043-y$

Willner P. The chronic mild stress (CMS) model of depression: history, evaluation and usage. Neurobiol Stress 2017; 6: 78-93. https://doi.org/10.1016/j.ynstr.2016.08.002

Willner P. Validity, reliability and utility of the chronic mild stress model of depression: a 10-year review and evaluation. Psychopharmacology 1997; 134: 319-29. https://doi.org/10.1007/s002130050456

Wu GF, Ren S, Tang RY, Xu C, Zhou JQ, Lin SM, et al. Antidepressant effect of taurine in chronic unpredictable mild stress-induced depressive rats. Sci Rep 2017; 7: 1-4. https://doi.org/10.1038/s41598-017-05051-3

Xu B, Lang LM, Lian S, Guo JR, Wang JF, Yang HM, et al. Oxidation stress-mediated MAPK signaling pathway activation induces neuronal loss in the CA1 and CA3 regions of the hippocampus of mice following chronic cold exposure. Brain Sci 2019; 9: 273. https://doi.org/10.3390/ brainsci9100273

Xue MQ, Quan HF, Wang R, Zhao XX, Yan L, Zhu YF, et al. Mitigation of chronic unpredictable stress-induced cognitive deficits in mice by Lycium barbarum L (Solanaceae) polysaccharides. Trop J Pharm Res 2017; 16: 1893-901. https://doi.org/10.4314/tjpr.v16i8.20

Yang XH, Song SQ, Xu Y. Resveratrol ameliorates chronic unpredictable mild stress-induced depression-like behavior: involvement of the HPA axis, inflammatory markers, BDNF, and Wnt/ $\beta$-catenin pathway in rats. Neuropsych Dis Treat 2017; 13: 2727. https://doi.org/10.2147/NDT. S150028

Yaribeygi H, Panahi Y, Sahraei H, Johnston TP, Sahebkar A. The impact of stress on body function: A review. EXCLI J 2017; 16: 1057.

Yazdi A, Doostmohammadi M, Majarshin FP, Beheshti S. Betahistine, prevents kindling, ameliorates the behavioral comorbidities and neurodegeneration induced by pentylenetetrazole. Epilepsy Behav 2020; 105: 106956. https://doi.org/10.1016/j.yebeh.2020.106956

Zhang H, Wei M, Sun Q, Yang T, Lu X, Feng X, et al. Lycopene ameliorates chronic stress-induced hippocampal injury and subsequent learning and memory dysfunction through inhibiting ROS/JNK signaling pathway in rats. Food Chem Toxicol 2020; 111688. https://doi.org/10.1016/j. fct. 2020.111688 